\title{
Patent Vitellointestinal Duct: A Close Differential Diagnosis of Umbilical Granuloma: A Case Report and Review of Literature
}

\author{
Saurabh Piparsaliya ${ }^{1}$, Milind Joshi ${ }^{2}$, Nitin Rajput ${ }^{1}$, Priti Zade ${ }^{1}$ \\ ${ }^{1}$ Department of pediatrics, Sri Aurobindo Institute of Medical Sciences, Indore, India \\ ${ }^{2}$ Department of pediatric surgery, Sri Aurobindo Institute of Medical Sciences, Indore, India \\ Email:milindj79@yahoo.com \\ Received January 27, 2011; revised April 2, 2011; accepted April 17, 2011
}

\begin{abstract}
Umbilical granuloma is a very common cause of umbilical discharge. It is managed by chemical cauterization or simple thread ligation. However, it can be a differential diagnosis of patent vitello intestinal duct and this should be ruled out before managing such patients. We report a case of a 10-week-old male infant referred by his General Practitioner for silver nitrate cauterisation, with a diagnosis of suspected umbilical granuloma (UG). The child underwent subsequent exploratory laparotomy and bowel anastomosis.
\end{abstract}

Keywords: Umbilical Granuloma, Patent Vitello Intestinal Duct, Umbilical Discharge

\section{Introduction}

Discharge from umbilicus is a very common presentation in pediatric age group and umbilical granuloma being the most common differential diagnosis in such patients. It is commonly managed by simple thread ligation of the granuloma or by chemical cauterization. Patent vitellointestinal duct should be ruled out in such patients to avoid catastrophy. The authors report the case of a 10week-old male infant referred by his General Practitioner for silver nitrate cauterisation, with a diagnosis of suspected umbilical granuloma (UG). The child underwent subsequent exploratory laparotomy and bowel anastomosis was performed after excision of the patent vitello intestinal duct.

\section{Case Report}

A 10-week-old male infant was referred with pink tissue protruding from the umbilicus. The infant was otherwise well with no vomiting, abdominal distension or any other signs of intestinal obstruction. He was born at term by emergency caesarean section following failure to progress, to a primigravida mother. He did not require resuscitation and weighed $3.47 \mathrm{~kg}$ at birth. The pregnancy itself had been unremarkable with no history of polyhydramnios and a normal prenatal ultrasound scan.

Both parents had noted the unusual nature of the in- fant's umbilicus following cord separation. Its size had doubled from the time it was first noticed and although there had been no discharge, some contact bleeding had been observed. The umbilical tissue did not appear to increase in size on crying. Following initial reassurances from their health visitor, the infant was referred by their General Practitioner when the tissue failed to subside at 10 weeks.

On examination the infant was well grown, comfortable and had no abdominal distension. Pink-red, fleshy tissue, about $1 \mathrm{~cm}$ in diameter, protruded from the umbilicus. There was no discharge from the umbilicus ei-

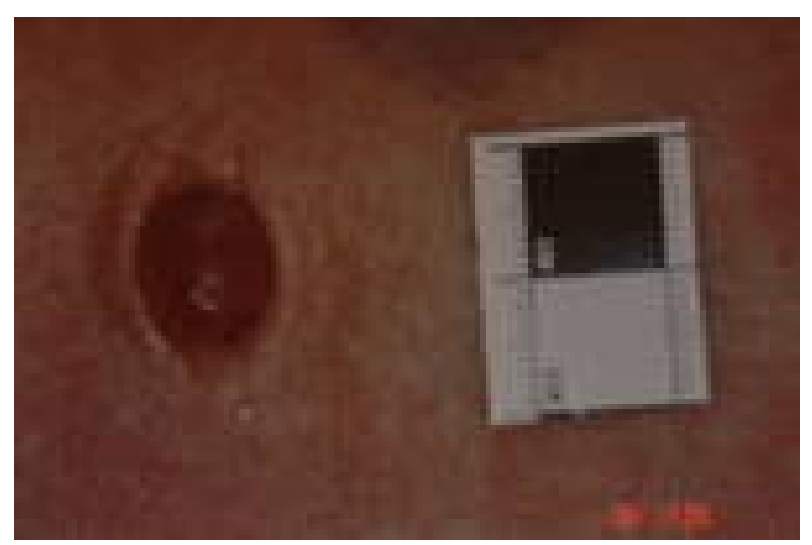

Figure 1. Clinical photograph showing patent vitellointestinal duct presenting as umbilical granuloma. 
ther superficially or on gentle palpation (Figure 1). It is quite understandable how, on cursory examination, this could have been misdiagnosed as an UG. However, more detailed inspection suggested that this was not typical granulation tissue; rather the tissue had the appearance of intestinal mucosa.

An abdominal ultrasound was organised, demonstrating divarication of the recti at the level of the umbilicus with protrusion of small bowel through these muscles (Figure 2). A connection between the umbilicus and the intestine was also noted and the diagnosis of VID remnant (or umbilical adenoma) was made. The dome of the urinary bladder was reported as normal and no umbilical connection was seen.

Following further assessment by the paediatric surgi- cal team, operative correction has been done for the patent Vitello Intestinal duct.

\section{Discussion}

The umbilical cord is formed following the fusion of the yolk stalk, containing the VID, the body stalk, which contains the two umbilical arteries and the umbilical vein and the allantois. Umbilical abnormalities can arise from any retained umbilical cord elements and may present clinically with inflammation, discharge, a palpable mass or a hernia, either singly or in combination. Umbilical disorders can be classified according to embryonic remnants contained in the umbilicus, including the urachus, the VID, the round ligament of the liver,

Table 1. All things "umbilical”.

\begin{tabular}{|c|c|}
\hline Condition & Aetiology \\
\hline A. Single Umbilical Artery & $\begin{array}{l}\text { Isolated (more common) } \\
\text { Associated with congenital anomalies }\end{array}$ \\
\hline B. Urachal abnormalities & Congenital \\
\hline i. Urachal Sinus & Distally patent urachus \\
\hline ii. Urachal Diverticulum & Proximally patent urac hus \\
\hline iii. Urachal Cyst & Patent mid -portion of urachus \\
\hline iv. Vesicoumbilical fistula & Complete patency of urachus \\
\hline v. Alternating sinus & $\begin{array}{l}\text { Cyst communicating with both umbilicus and } \\
\text { bladder }\end{array}$ \\
\hline C. VID abnormalities & Congenital \\
\hline i. Umbilical Adenoma / Polyp & Distal VID remnant \\
\hline ii. Vitelline Sinus & Distally patent VID \\
\hline iii. Meckel's Diverticulum & Proximally patent VID \\
\hline iv. Vitelline Cyst & Patent mid -portion of VID \\
\hline v. Umbilical fistula & Complete patency of VID \\
\hline vi. Fibrous bands & Fibrous remnants of VID \\
\hline D. Umbilical ring abnormalities & Acquired $(A)$ or Congenital $(C)$ \\
\hline i. Umbilical hernia & $\begin{array}{l}\text { Failure of closure of the umbilical ring after cord } \\
\text { separation }(A)\end{array}$ \\
\hline ii. Gastroschisis & $\begin{array}{l}\text { Paraumbilical muscular defect in anterior } \\
\text { abdominal wall }(\mathrm{C})\end{array}$ \\
\hline iii. Exomphalos & $\begin{array}{l}\text { Failure of mid -gut to retract from umbilical cord } \\
\text { into the abdomen }(\mathrm{C})\end{array}$ \\
\hline iv. Omphalocoele & $\begin{array}{l}\text { Defect of anterior a bdominal wall due to } \\
\text { incomplete closure of umbilical ring }(C)\end{array}$ \\
\hline $\begin{array}{l}\text { D. Round Ligament of liver } \\
\text { i. Recanalisation of portal vein. }\end{array}$ & Portal hypertension \\
\hline $\begin{array}{l}\text { E. Extraperitoneal paravesical } \\
\text { spaces }\end{array}$ & \\
\hline i. Fluid collections & Several \\
\hline $\begin{array}{l}\text { F. Inflamm atory and related } \\
\text { disorders }\end{array}$ & Inflammatory process \\
\hline i. Umbilical granuloma & $\begin{array}{l}\text { Overgrowth of granulation tissue and low-grade } \\
\text { infection }\end{array}$ \\
\hline ii. Omphalitis & Simple infection \\
\hline iii. Necrotising fasciitis & Polymicrobial infection \\
\hline $\begin{array}{l}\text { iv. Leucocyte adhesion } \\
\text { deficiency }\end{array}$ & Neutrophil chemotaxis disorder \\
\hline G. Neoplastic disorders & Primary and Secondary \\
\hline
\end{tabular}

Common disorders are underlined. Others are relatively rare. 

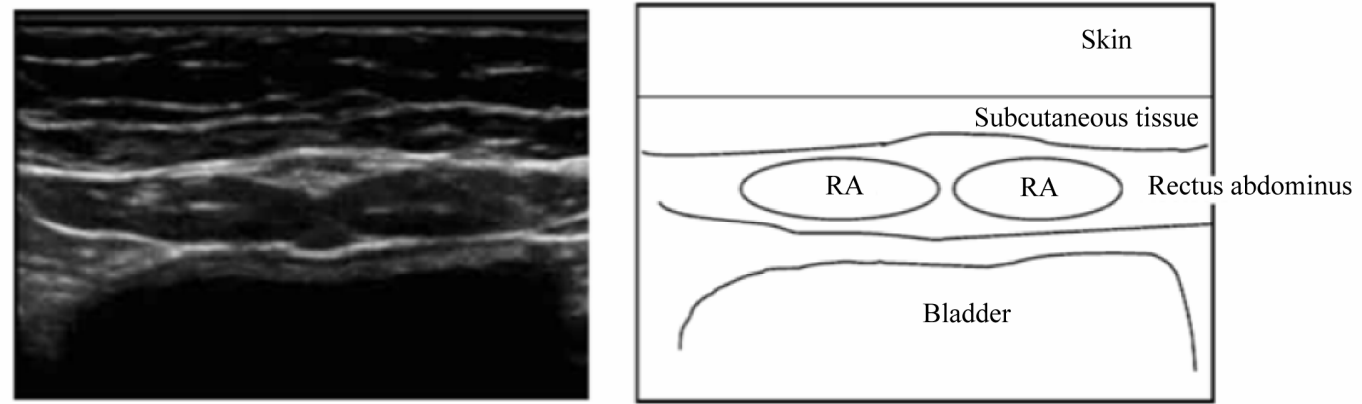

(a)
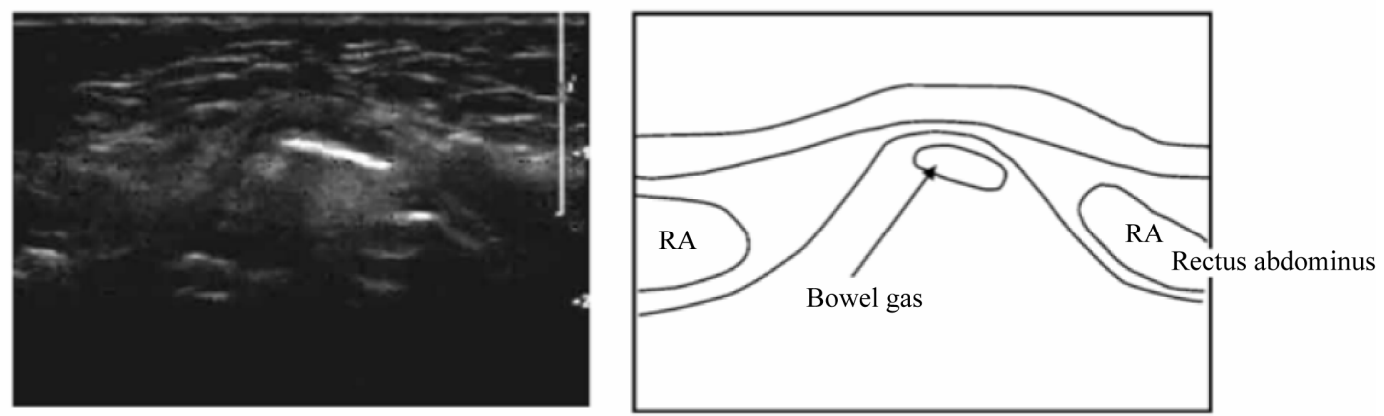

(b)

Figure 2. Ultrasound finding suggestive of patent vitellointestinal duct with schematic representation. (a) Normal anatomical arrangement (Seen with ultrasound"slice"at level of bladder); (b) Anatomical defect in rectus sheath (Seen with ultrasound "slice" at level of defect).

the extraperitoneal paravesical spaces, the umbilical ring and the umbilicus itself (Table 1).

Umbilical granulomas (UG) are the commonest umbilical abnormalities encountered in neonatal practice. UG is not a true congenital abnormality, but represents ongoing inflammation and granulation tissue formation, of an umbilicus that has yet to epithelialise. [1] Classically, they are round, moist, erythematous, pedunculated and usually between 3 and $10 \mathrm{~mm}$ in diameter. Bacterial colonisation and low-grade infection may play a role in their pathogenesis. The common treatment is cauterisation with $75 \%$ Silver Nitrate, usually repeated two to three times. Rarely, persistent UG need surgical removal. If a presumed UG fails to respond to cauterisation, alternative diagnoses must be considered (Table 1).

The congenital remnants of the urachus and VID can pose diagnostic difficulties, as their clinical manifestations are often non-specific and they can resemble umbilical granulomas [2-4]. Ultrasound imaging may be used to distinguish these lesions by identifying their relationship to, and their continuity with, the umbilicus and the urinary bladder [5], and has avoided unnecessary surgical exploration [6]. Sometimes, if the clinical presentation is suspicious then injecting contrast material into the patent tract and having a roentgenogram also helps in confirming the diagnosis.

In conclusion, UG is a common clinical problem in general and neonatal practice, typically treated with silver nitrate. However, careful examination is essential to exclude other umbilical conditions requiring surgical intervention, in which the consequences of silver nitrate cauterisation can be disastrous [4].

\section{References}

[1] A. Pomeranz, "Anomalies, Abnormalities, and Care of the Umbilicus," Pediatric Clinics of North America, Vol. 51, No. 3, 2004, pp. 819-827. doi:10.1016/j.pcl.2004.01.010

[2] K. A. O’Donnell, P. L. Glick and M. G. Caty, "Pediatric Umbilical Problems," Pediatric Clinics of North America, Vol. 45, No. 4, 1998, pp. 791-799. doi:10.1016/S0031-3955(05)70045-6

[3] B. P. Van Bezooijen, H. J. van der Horst and C. Sleeboom, "The Wet Umbilicus: Maybe Not an Umbilical Granuloma?” Ned Tijdschr Geneeskd, Vol. 146, No. 29, 2002, pp. 1345-1348.

[4] J. Campbell, S. W. Beasley, N. McMullin and J. M. Hutson, "Clinical Diagnosis of Umbilical Swellings and Discharges in Children,” The Medical Journal of Australia, Vol. 145, No. 9, 1986, pp. 450-453.

[5] N. J. Khati, E. G. Enquist and M. C. Javitt, "Imaging of the Umbilicus and Periumbilical Region,” Radiographics, Vol. 18, No. 2, 1998, pp. 413-431.

[6] A. E. Boothroyd and R. E. Cudmore, "Ultrasound of the Discharging Umbilicus,” Pediatric Radiology, Vol. 26, No. 5, 1996, pp. 362-364. doi:10.1007/BF01395717 